\title{
Cucurbitacin B inhibits growth, arrests the cell cycle, and potentiates antiproliferative efficacy of cisplatin in cutaneous squamous cell carcinoma cell lines
}

\author{
WEIKAI CHEN ${ }^{1,2}$, AMANDA LEITER ${ }^{2}$, DONG YIN ${ }^{2}$, MURIEL MEIRING $^{1}$, \\ VERNON J. LOUW ${ }^{4}$ and H. PHILLIP KOEFFLER ${ }^{2,3}$
}

\begin{abstract}
${ }^{1}$ Department of Hematology and Cell Biology, Faculty of Health Sciences, University of the Free State, Bloemfontein 9301, Free State, South Africa; ${ }^{2}$ Division of Hematology and Oncology, Cedars-Sinai Medical Center, University of CaliforniaLos Angeles School of Medicine, Los Angeles, CA 90048, USA; ${ }^{3}$ National Cancer Institute of Singapore and CSI, Singapore;

${ }^{4}$ Division of Clinical Haematology, Department of Internal Medicine, Faculty of Health Sciences, University of the Free State, Bloemfontein 9301, Free State, South Africa
\end{abstract}

Received March 24, 2010; Accepted May 7, 2010

DOI: 10.3892/ijo_00000723

\begin{abstract}
Cutaneous squamous cell carcinoma (CSCC) is the second most common skin cancer with a substantial risk of metastasis which causes clinical treatment failure. This study investigated the anti-CSCC effects of a triterpenoid compound, Cucurbitacin $\mathrm{B}(\mathrm{CuB})$. Dose-response studies showed that $\mathrm{CuB}$ inhibited $50 \%$ growth $\left(\mathrm{ED}_{50}\right)$ of the CSCC cell lines (SRB1, SRB12, SCC13, COLO16) in liquid culture at $4 \times 10^{-7}$ $-10^{-5} \mathrm{M}$. Soft-agar assays demonstrated that nearly all of the CSCC clonogenic cells were inhibited at $10^{-7} \mathrm{M} \mathrm{CuB}$. FACS analysis found that the compound $\left(10^{-7} \mathrm{M}, 48 \mathrm{~h}\right)$ caused $\mathrm{G} 2 / \mathrm{M}$ arrest. The CSCC cells underwent profound morphologic changes within $60 \mathrm{~min}$ after exposure to $\mathrm{CuB}\left(10^{-7} \mathrm{M}\right)$, rounding up and losing their pseudopodia. $\mathrm{CuB}\left(10^{-7} \mathrm{M}\right)$ caused prominent multinucleation of the cells after they were pulse-exposed $(24 \mathrm{~h})$ to the drug, washed and cultured in normal medium for an additional $24 \mathrm{~h}$. The drug $\left(10^{-8}-10^{-6} \mathrm{M}\right.$, 3-24 h) decreased levels of CDC2 and cyclin B1 in SRB1 and SRB12 cell lines as seen by Western blot analysis. Migration of SRB1 and SRB12 cells was inhibited by $10^{-7} \mathrm{M} \mathrm{CuB}$. Interestingly, $\mathrm{CuB}$ synergistically potentiated the anti-proliferative effect of cisplatin in CSCC. In summary, $\mathrm{CuB}$ has a prominent anti-proliferative activity on CSCC cells. In vivo studies and clinical trials of this drug should be pursued in CSCC.
\end{abstract}

\section{Introduction}

CSCC is the second most common skin cancer representing $20 \%$ of all cutaneous malignancies (1-3). In addition, the

Correspondence to: Dr Dong Yin, Division of Hematology and Oncology, Cedars-Sinai Medical Center, UCLA School of Medicine, 8700 Beverly Boulevard, Davis building, 5022 Room, Los Angeles, CA 90048, USA

E-mail: dong.yin@cshs.org

Key words: cucurbitacin B, cell cycle, cisplatin, cutaneous squamous cell carcinoma incidence of CSCC appears to be rising (3). CSCC tends to locate on the skin of the head and neck (4) and has a substantial risk of metastasis to local lymph nodes and to distant organs $(3,5)$. For those patients with metastatic disease as well as those with a poor prognosis (5), systemic chemotherapy is the standard treatment $(5,6)$. The platinum compound cisplatin is regarded as a standard chemotherapeutic agent used either alone or in combination with other agents against CSCC (7). However, cisplatin is associated with a variety of side-effects, including the relapse of most cancers after therapy and eventual resistance to cisplatin. Therefore, new effective anti-CSCC therapeutic regimens are needed.

Natural herbal medicines have been used as anticancer agents (8). Cucurbitacins are a group of highly structurally diverse tetracyclic triterpenes isolated from numerous plant families such as the Cucurbitaceae and Cruciferae, which possess a wide spectrum of pharmacological effects such as cytotoxicity, chemoprevention, antitumor properties, hepatoprotective, analgesic, anti-inflammatory, antimicrobial, antihelmintic, as well as procardiovascular activities $(8,9)$. This family of compounds has been used as folk medicines for centuries in Asia, especially China and India $(9,10)$. Chemically, cucurbitacins are highly diverse compounds and are arbitrarily divided into twelve categories (cucurbitacins A-T) (11). Of these compounds, $\mathrm{CuB}$ is one of the most abundant and has been most widely used $(10,12)$. Recent studies have suggested that $\mathrm{CuB}$ inhibits the growth of numerous human cancer cell lines and tumor xenografts, including leukemias, lymphomas, multiple myelomas, melanomas and cancers of oral cavity, nasopharynx, breast, prostate, lung, uterine cervix, liver, and brain $(10,11,13)$. The anti-tumor mechanism of $\mathrm{CuB}$ involves a variety of effects including induction of apoptosis, and/or differentiation, arrest of the cell cycle, disruption of the cytoskeleton as well as interruption of several signal transduction pathways (14-17). However, the effect of $\mathrm{CuB}$ and its underlying mechanism of action against CSCC are unexplored. 
In the present study, we evaluated the action of $\mathrm{CuB}$ on CSCC cell lines. CuB significantly inhibited the proliferation as well as metastasic potential of CSCC cell lines. $\mathrm{CuB}$ caused a marked G2-M phase arrest and increased apoptosis. It also produced a rapid alteration of cell morphology including rounding of the outer cell membrane and prominent multinucleation. Moreover, the compound significantly potentiated the anti-proliferative effects of cisplatin against CSCC cells.

\section{Materials and methods}

CSCC cell lines, cell proliferation and migration. Human CSCC cell lines SRB1, SRB12, SCC13, COLO16 (kindly provided by Dr Reuben Lotan, MD Anderson Cancer Center) were maintained in Dulbecco's modified Eagle's medium (Gibco-BRL) with 10\% fetal calf serum (Gemini Bio-Products, Calabasas, CA), $10 \mathrm{U} / \mathrm{ml}$ penicillin-G, and $10 \mathrm{mg} / \mathrm{ml}$ streptomycin (Gemini Bio-Products). The cells were incubated at $37^{\circ} \mathrm{C}$ in $5 \% \mathrm{CO}_{2}$. For pulse-exposure experiments, cells were exposed to $\mathrm{CuB}\left(10^{-7} \mathrm{M}\right)$ for either 2,9 or $24 \mathrm{~h}$, washed extensively with culture medium and grown in $\mathrm{CuB}$-free medium for 1, 2, 3 days. For clonogenic assays, cells were plated into 24-well flat-bottomed plates using a two-layer soft agar system with a total of $3 \times 10^{3}$ cells/well in a volume of $400 \mu \mathrm{l} /$ well, as described previously (15). After 14 days of incubation, the colonies were counted. For proliferation measurements, the cells were placed into 96-well plates, and cell growth was measured at various times by 3-(4,5-Dimethylthiazol-2-yl)-2,5-diphenyltetrazolium bromide (MTT) assay according to the protocol provided by Roche Molecular Biochemicals (Basel, Switzerland). For cell migration assays, SRB1 and SRB12 cell lines were seeded into 12-well flatbottomed plates until $80 \%$ confluence. Distance of migration was measured microscopically, one half of the dish was physically cleared of cells, the leading edge of cells was marked microscopically, fresh medium was added and incubated either with or without $\mathrm{CuB}$ for $24 \mathrm{~h}$, then the distance of migration was measured on the bottom of the plate.

Chemicals. CuB was provided by CK Life Sciences Ltd. (Hong Kong) and was dissolved in DMSO at a stock concentration of $10^{-2} \mathrm{M}$ and stored at $-20^{\circ} \mathrm{C}$. Fresh dilutions in medium were made for each experiment.

Assessment of apoptosis. To study induction of apoptosis, Annexin V assays (Annexin VFITC Apoptosis Detection kit; Pharmingen, San Diego, CA) were performed according to the manufacturer's instructions. Briefly, cells were harvested after exposure to reagents, washed twice with PBS, incubated with FITC-conjugated annexin V and Propidium Iodide (PI) for 15 min; staining was measured by FACScan (BectonDickinson).

Cell cycle analysis. CSCC cells were placed in 6-well dishes and cultured for $24 \mathrm{~h}$ with $\mathrm{CuB}$. After trypsinization and washing twice with ice-cold phosphate-buffered saline (PBS), cells were fixed in $70 \%$ ice-cold ethanol overnight. The samples were treated by RNAase A and exposed to propidium iodide (PI), then analyzed by flow cytometry (FACScan, Becton-Dickinson).
Western blot analysis. Cells were harvested for total cell lysates with RIPA buffer (1\% Nonidet P-40, 0.5\% sodium deoxycholate, $0.1 \%$ SDS, $50 \mathrm{mM}$ Tris- $\mathrm{HCl}, \mathrm{pH}$ 7.5) containing a mixture of protease inhibitors (Roche Diagnostics $\mathrm{GmbH}$, Mannheim, Germany), as well as $1 \mathrm{mM} \mathrm{NaF}$ and $1 \mathrm{mM}$ $\mathrm{NaVO}_{4}$. Cell lysates were centrifuged at 13,000 rpm for $10 \mathrm{~min}$ at $4^{\circ} \mathrm{C}$. Supernatants were collected, and the concentration of proteins was measured. The proteins in the lysates $(30 \mu \mathrm{g})$ were denatured in the sample buffer (10\% glycerol, $5 \%$ Bmercaptoethanol, 2.3\% SDS, $62.5 \mathrm{mM}$ Tris- $\mathrm{HCl}, \mathrm{pH}$ 6.8) by boiling and then subjected to 4-15\% SDS-PAGE followed by electro-transfer to polyvinylidene difluoride membrane. The immune complexes were visualized with Supersignal west dura extended duration substrate (Pierce, Rockford, IL) and normalized by an internal control (GAPDH). The antibodies were purchased from Santa Cruz Biotechnology, CA.

Statistical analysis. Differences between the results of experimental treatments were evaluated by the t-test. Differences were considered significant at values of $\mathrm{p}<0.05$.

\section{Results}

$C u B$ inhibits proliferation in liquid and soft gel culture of CSCC cells as well as decreases their migration. We tested the ability of $\mathrm{CuB}$ to inhibit the proliferation of CSCC cell lines (SRB1 and SRB12) in liquid culture using the MTT assay (Fig. 1A). The SRB12 cells were the most sensitive to $\mathrm{CuB}$ with an $\mathrm{ED}_{50}$ of about $4 \times 10^{-7} \mathrm{M}$ at $72 \mathrm{~h}$ of $\mathrm{CuB}$ exposure. Two other CSCC cell lines (SCC13 and COLO16) were less sensitive to this compound with an $\mathrm{ED}_{50}$ about $10^{-5} \mathrm{M} \mathrm{CuB}$ at $72 \mathrm{~h}$ exposure (data not shown).

Clonogenic assay depends on individual colony-forming cells proliferating actively in soft gel culture to form a colony. Clonal growth of CSCC was inhibited significantly by the drug in a dose-dependent manner compared with the control cells. At $10^{-7} \mathrm{M} \mathrm{CuB}$, nearly all of the clonogenic SRB1 cells were inhibited (Fig. 1B, data not shown). Furthermore, migration of SRB12 CSCC cells cultured with $\mathrm{CuB}\left(2.5 \times 10^{-7} \mathrm{M}\right.$, $24 \mathrm{~h}$ ) was significantly decreased compared with diluenttreated control cells (Fig. 1C).

$\mathrm{CuB}$ rapidly alters cell morphology, produces cell cycle arrest, and increases apoptosis of CSCC cells. The CSCC cell lines (SRB1 and SRB12) underwent rapid morphologic changes within 15-30 min after exposure to $\mathrm{CuB}\left(5 \times 10^{-7} \mathrm{M}\right)$, rounding up and losing their pseudopodia; by $120 \mathrm{~min}$, the cells were very irregular and refractile (Fig. 2A).

The ability of $\mathrm{CuB}$ to induce apoptosis in a time- and dose-dependent manner was measured by Annexin V-FITC and propidium iodide double labeling assay. A total of $9 \%$ (SRB12), 16\% (SCC13), and 26\% (COLO16) of the CSCC cells were apoptotic after a $48 \mathrm{~h}$ of drug exposure $\left(10^{-6} \mathrm{M}\right)$, whereas less than $2.5 \%$ of the diluent treated cells had undergone apoptosis (Fig. 2B).

The effect of $\mathrm{CuB}$ on the cell cycle was studied by flow cytometry (Fig. 2C). The compound caused a time- and dosedependent G2-M phase arrest of the cells (SRB12, SCC13 and COLO16). After $48 \mathrm{~h}$ of drug exposure $\left(10^{-6} \mathrm{M}\right)$, the percentage of cells in the G2-M phase increased by 5-10 fold compared with the controls. We further examined the 
expression of several proteins involved in cell cycle regulation. The protein levels of CDC2 and cyclin B1 decreased remarkably in a time- and dose-dependent fashion (Fig. 2D).

Influence of pulse-exposure to $C u B$ on cell proliferation and cell morphology of CSCC cells. We examined the proliferative activity of CSCC cell lines after they were pulse-exposed to $\mathrm{CuB}\left(10^{-7} \mathrm{M}\right)$ for either 2,9 , or $24 \mathrm{~h}$, washed extensively, and grown in liquid culture in the absence of $\mathrm{CuB}$ for an additional 24, 48 or $72 \mathrm{~h}$ (Fig. 3A). A significant decrease in proliferation

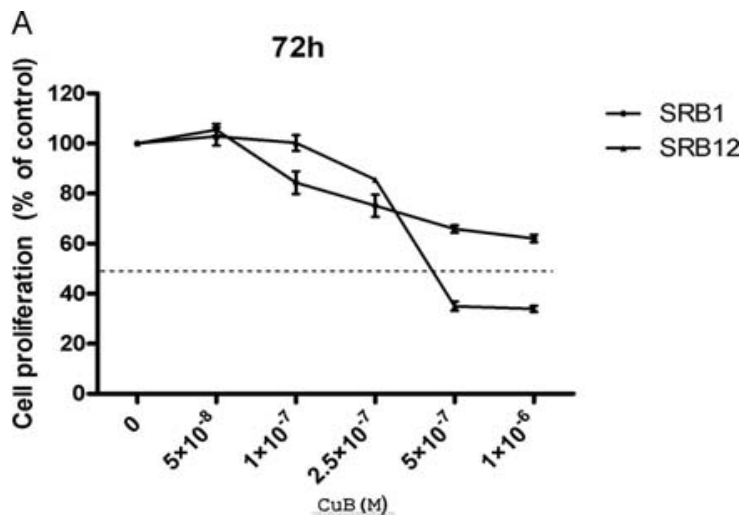

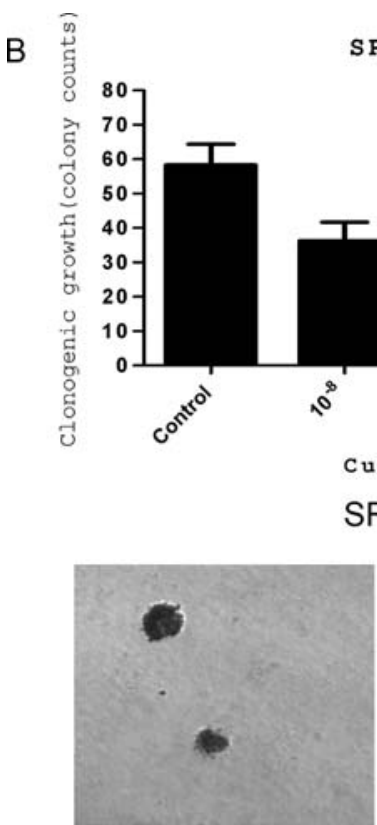

Diluent control

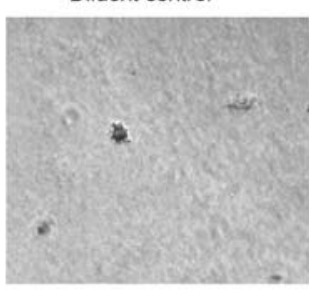

CuB10 $10^{-7} \mathrm{M}$
SRB 1

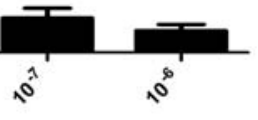

RB1

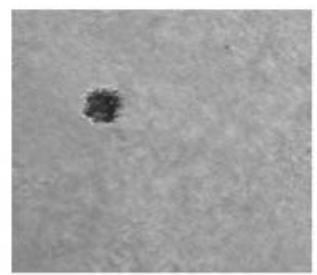

$\mathrm{CuB} 10^{-8} \mathrm{M}$

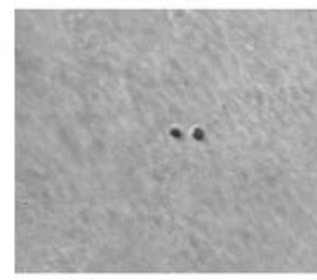

CuB10 $0^{-6} \mathrm{M}$

of the CSCC cells (SRB12) occurred after exposed for $24 \mathrm{~h}$ to $\mathrm{CuB}$ compared with diluent-exposed control cells (Fig. 3A; $\mathrm{p}<0.01)$. Only a slight decrease in proliferation of these cells was noted when exposed for either 2 or $9 \mathrm{~h}$.

In additional experiments, SRB12 cells were exposed to either $\mathrm{CuB}\left(2.5 \times 10^{-7} \mathrm{M}\right)$ or diluents for $24 \mathrm{~h}$, washed and recultured in drug-free media for another $24 \mathrm{~h}$ (Fig. 3B). CuB caused prominent multinucleation of the cells. After $24 \mathrm{~h}$ pulseexposure to $\mathrm{CuB}$ [SRB1 $\left(10^{-6} \mathrm{M}\right)$, SRB12 $\left(10^{-7} \mathrm{M}\right)$ ] followed by extensive washing and $24 \mathrm{~h}$ of culture in $\mathrm{CuB}$-free medium, a mean $23 \pm 3 \%$ SRB1 and $11 \pm 5 \%$ SRB12 cells developed marked polyploidy (predominantly tetraploidy) compared with $2 \pm 2 \%$ SRB1 and $4 \pm 3 \%$ SRB12 untreated control cells (Fig. 3C).

$C u B$ synergistically potentiates the anti-proliferative effects of cisplatin. The growth of SRB1 and SRB12 cells treated with $\mathrm{CuB}\left(10^{-7} \mathrm{M}\right.$ and $\left.2.5 \times 10^{-7} \mathrm{M}\right)$, cisplatin $(5,10$ and $20 \mu \mathrm{M})$, or a combination of both was determined by MTT assay (Fig. $4 \mathrm{~A}$ and $\mathrm{B})$. A significant reduction in growth was observed in the cell lines (SRB1 and SRB12) treated with a combination of $\mathrm{CuB}\left(2.5 \times 10^{-7} \mathrm{M}\right)$ and cisplatin $(10$ and/or $20 \mu \mathrm{M})$ $(\mathrm{p}<0.05)$.

C SRB12 0 time

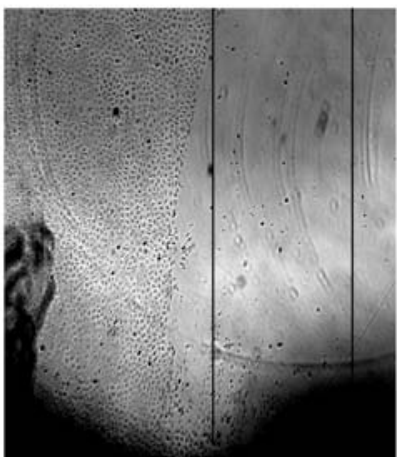

Diluent control

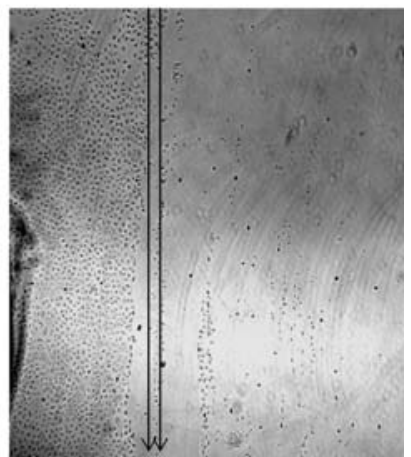

$2.5 \times 10^{-7} \mathrm{M} \mathrm{CuB}$

\section{4 hours culture}

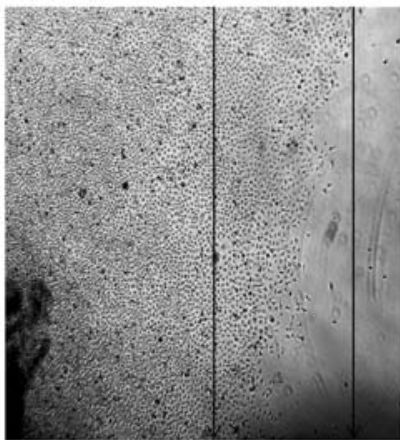

Diluent control

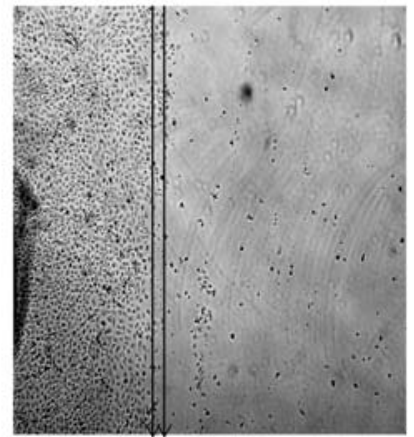

$2.5 \times 10^{-7} \mathrm{M} \mathrm{CuB}$

Figure 1. Effect of $\mathrm{CuB}$ on proliferation, clonal growth and migration of CSCC cells. (A) SRB1 and SRB12 CSCC cell lines were cultured in the presence of various concentrations $\left(5 \times 10^{-8}-1 \times 10^{-6} \mathrm{M}\right)$ of $\mathrm{CuB}$ for $72 \mathrm{~h}$. Cell proliferation was measured by MTT assay. Results are expressed as a mean percentage of MTT activity present in the diluent only control wells. Each point represents a mean \pm standard deviation (SD) of 3 independent experiments done in triplicate. (B) CSCC cell line SRB1 was cultured in 2 layer soft agar either without or with CuB $\left(10^{-8}-10^{-6} \mathrm{M}\right)$, and colonies were counted after 14 days. Photographs show representative results of the colony assay. (C) Migration assay: SRB12 CSCC cells were cultured either without or with CuB (2.5x10-7 M) for $24 \mathrm{~h}$, and cellular migration was measured. Photographs were taken at the same position and magnification with marks at 0 and $24 \mathrm{~h}$ (representive results shown for each cell line) 
A

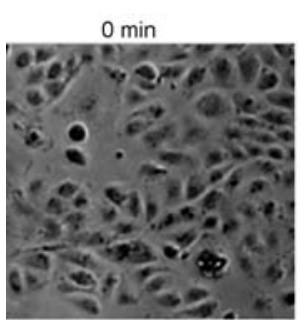

SRB1

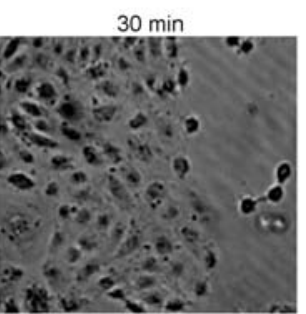

$2.5 \times 10^{-7} \mathrm{M}$ CuB

SRB12
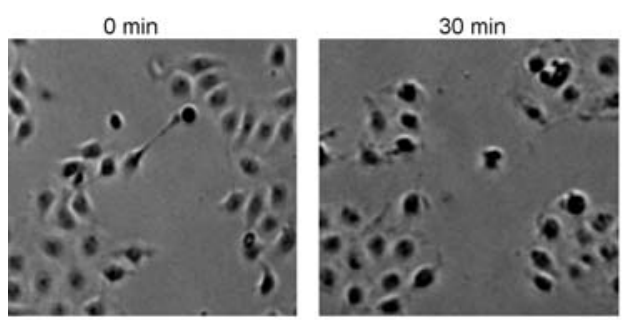

$2.5 \times 10^{-7} \mathrm{M} \mathrm{CuB}$

B (a)

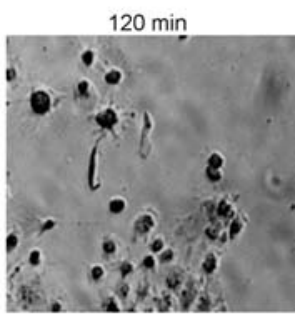

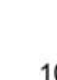
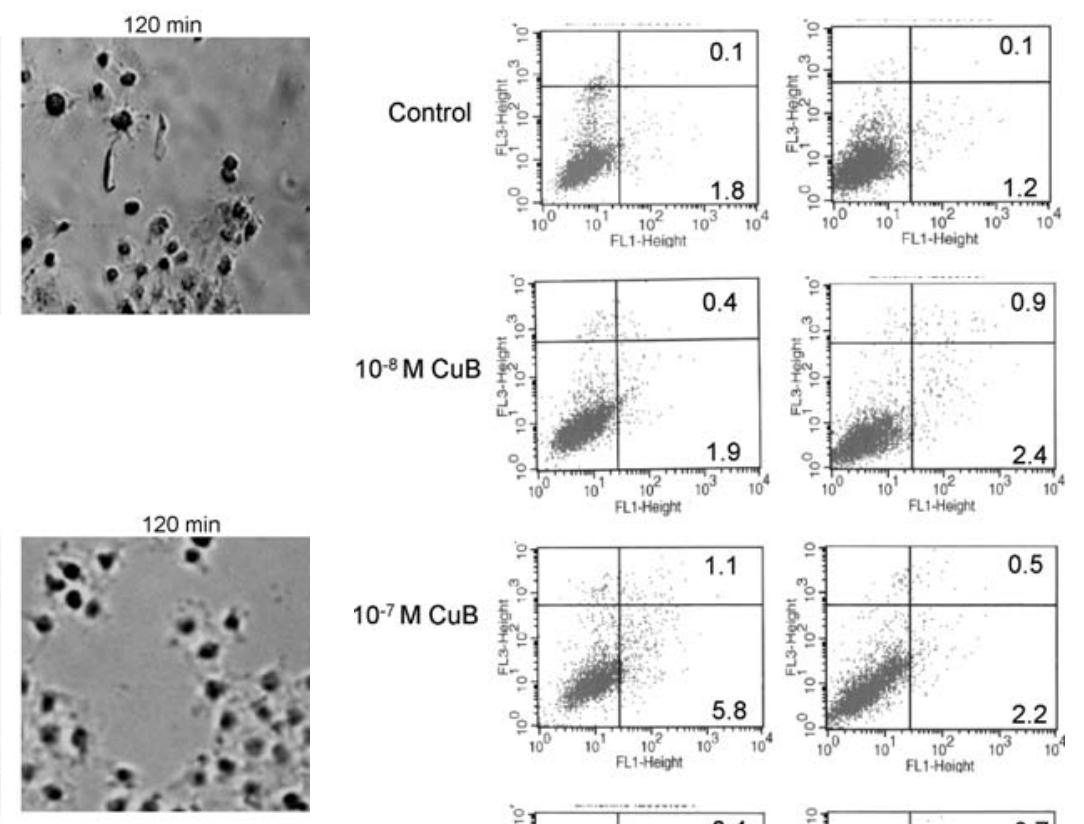

${ }^{10^{-6} \mathrm{M} \mathrm{CuB}}$

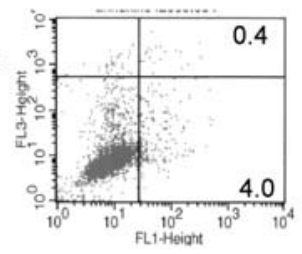

$24 \mathrm{~h}$

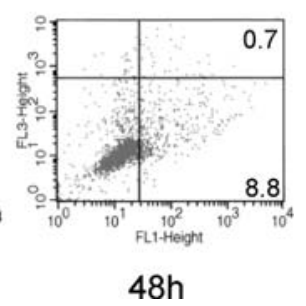

B (c)

COLO16
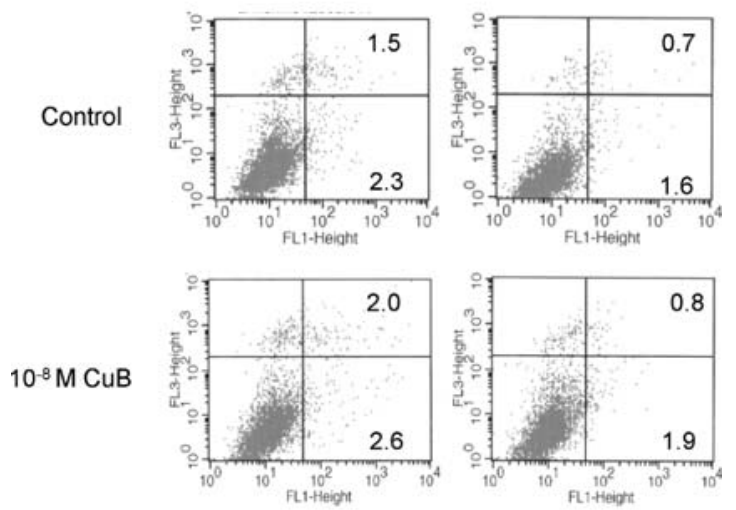

$10^{-7} \mathrm{M} \mathrm{CuB}$
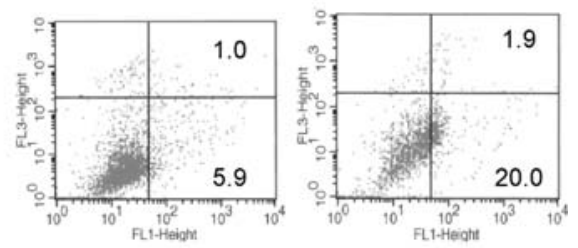

$10^{-6} \mathrm{M} \mathrm{CuB}$

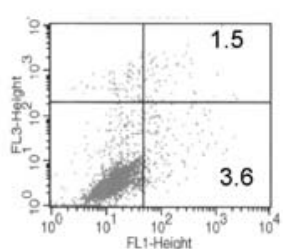

24h

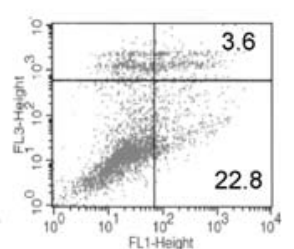

$48 \mathrm{~h}$

Figure 2. $\mathrm{CuB}$ alters cell morphology, arrests cells in $\mathrm{G} 2-\mathrm{M}$ cell cycle, and induces apoptosis. (A) After exposed to CuB (5x10-7 $\mathrm{M}$ for either 0 , 30 or 120 min), morphology of SRB1 and SRB12 CSCC cells were examined. (B) CSCC cells (SRB12, SCC13 and COLO16) were cultured either without or with CuB $\left(10^{-8}-10^{-6} \mathrm{M}\right)$. After 24 and $48 \mathrm{~h}$, apoptosis was measured by Annexin V/PI assay. Representative results are shown (three experiments were performed, each with similar results). 
C
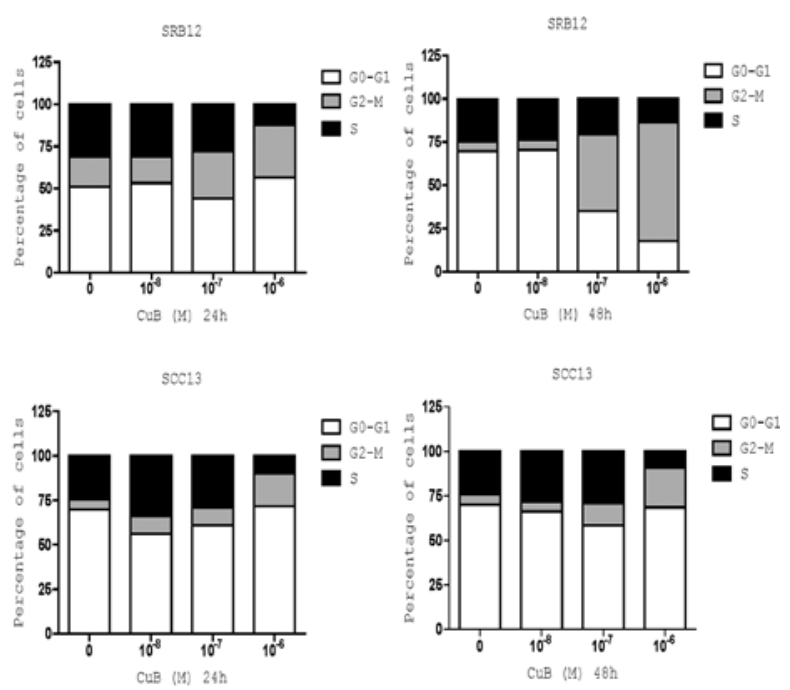

CoL016
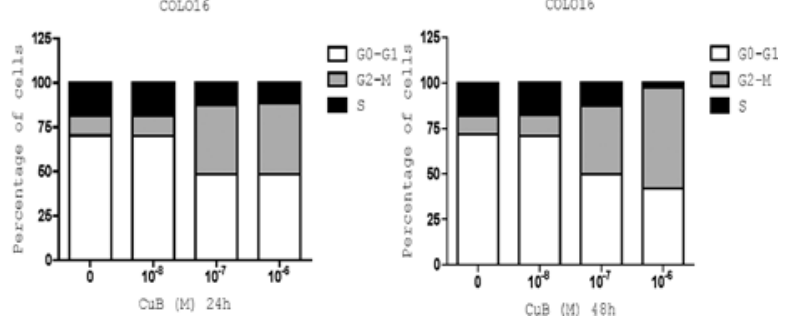

A

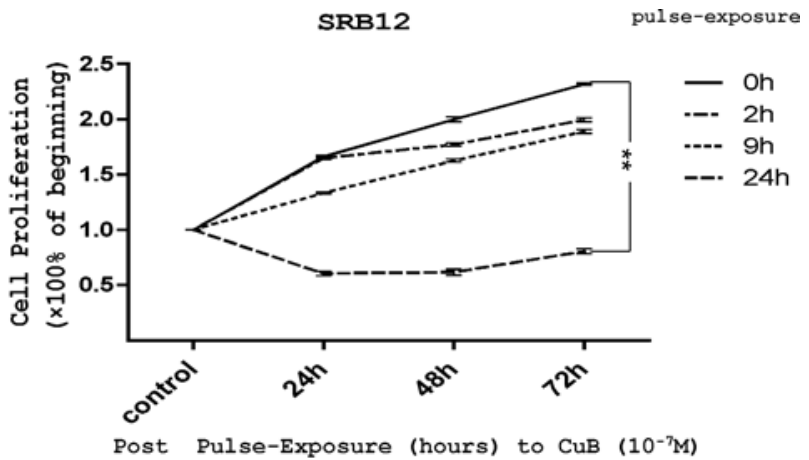

B

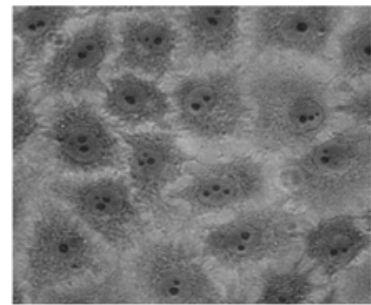

Diluent control
SRB12

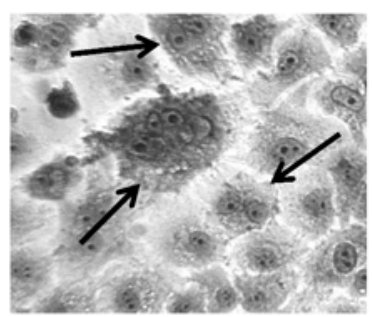

CuB pulse exposure and cultured
D

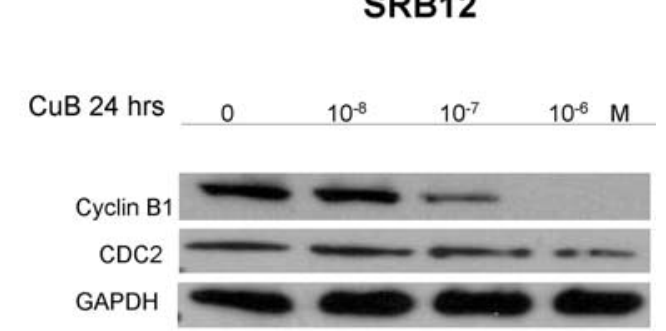

CuB $10^{-6} \mathrm{M}$

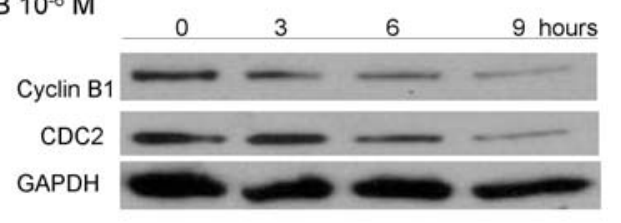

Figure 2. Continued. (C) Cell cycle distribution of CSCC cells (SRB12, SCC13 and COLO16) was analyzed after culturing for 24 and $48 \mathrm{~h}$ either without or with $\mathrm{CuB}\left(10^{-8}-10^{-6} \mathrm{M}\right)$. Cell cycle was assessed by propidium iodide staining and FACS analysis. For each sample, the percentage of cells in $\mathrm{G} 0 / \mathrm{G} 1, \mathrm{~S}$ or $\mathrm{G} 2 / \mathrm{M}$ phase of the cell cycle is indicated. Representive result is shown (two additional experiments gave similar results). (D) Western blot: SRB12 cells were exposed to either $\mathrm{CuB}\left(10^{-8}-10^{-6} \mathrm{M}\right)$ for $24 \mathrm{~h}$ (upper panel) or to $10^{-6} \mathrm{M} \mathrm{CuB}$ for 3, 6, and $9 \mathrm{~h}$ (lower panel), lysates were made and Western blot analysis was performed using antibodies against cyclin B1, cdc2 and GAPDH (loading control).
C

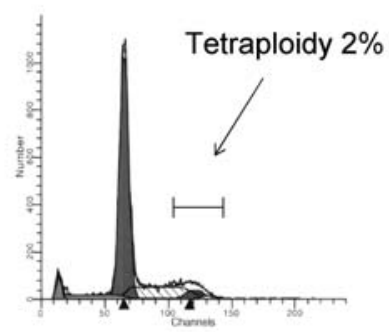

Diluent

\section{SRB12}

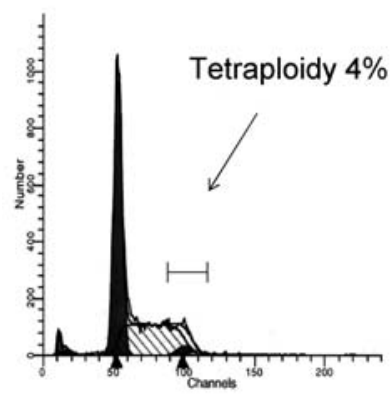

Diluent

SRB1

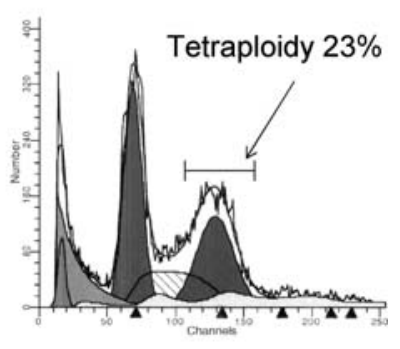

CuB Pulse Exposure

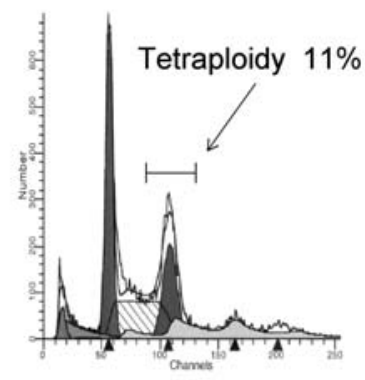

CuB Pulse Exposure

Figure 3. Influence of pulse-exposure to $\mathrm{CuB}$ on growth and cell morphology of CSCC cells. (A) SRB12 cells were exposed to CuB (10 $\left.{ }^{-7} \mathrm{M}\right)$ for 2,9 or $24 \mathrm{~h}$, washed extensively, cultured in CuB-free culture medium for 24,48 and $72 \mathrm{~h}$, and cell growth was measured by MTT assay. Each point represents a mean \pm SD of triplicate wells. (B) $\mathrm{CuB}$ causes multinucleation: SRB12 cells were treated with $\mathrm{CuB}\left(2.5 \times 10^{-7} \mathrm{M}\right.$ for 2 days), washed and cultured an additional 2 days with no $\mathrm{CuB}$, multinucleation developed, see arrows. (C) SRB1 or SRB12 cells were cultured with $\mathrm{CuB}\left(10^{-6} \mathrm{M}\right.$ or $10^{-7} \mathrm{M}$ for $\left.24 \mathrm{~h}\right)$, washed extensively and cultured in regular media for an additional $24 \mathrm{~h}$ and examined for DNA content per cell by FACS after staining with propidium iodine. Cells were gated using FL2-W versus FL2-A bivariant graphs. 
A

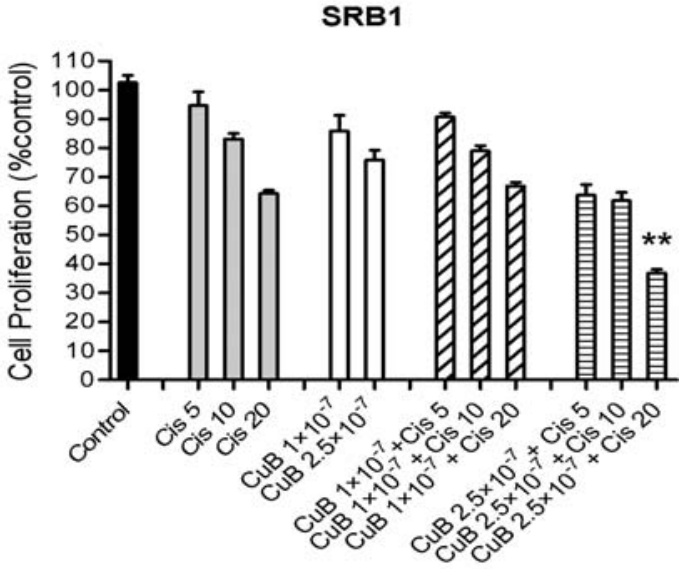

B

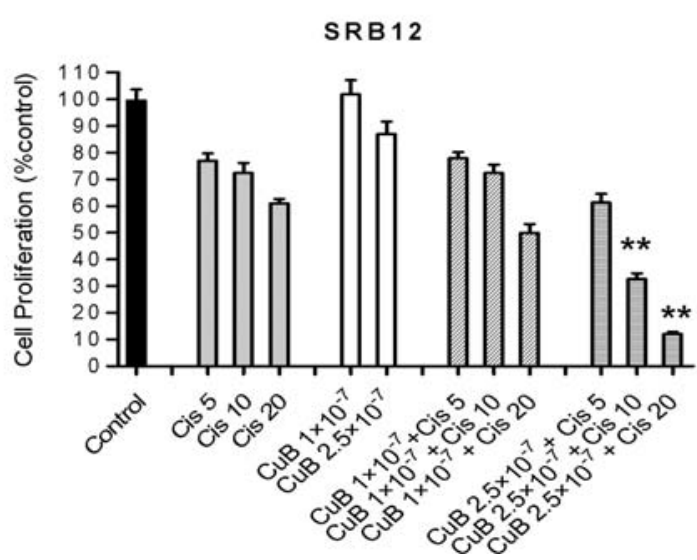

C

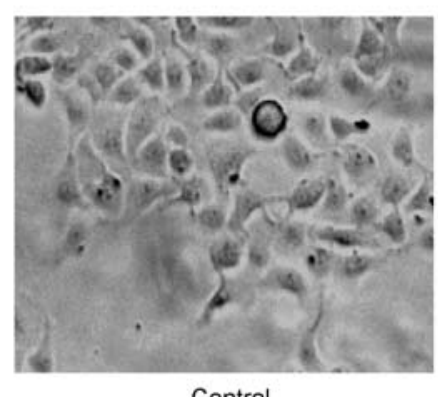

Control

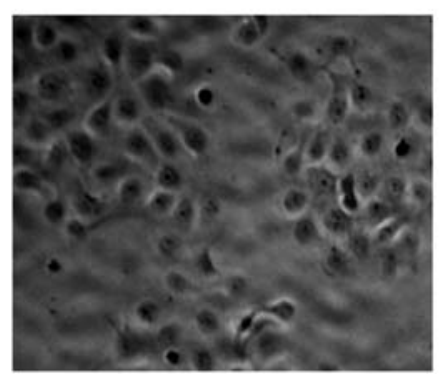

Cisplatin $10 \mu \mathrm{M}$ (36 hrs)
SRB12

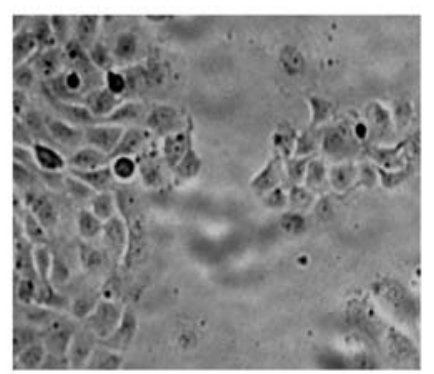

CuB $2.5 \times 10^{-7} \mathrm{M}$ (36 hrs)

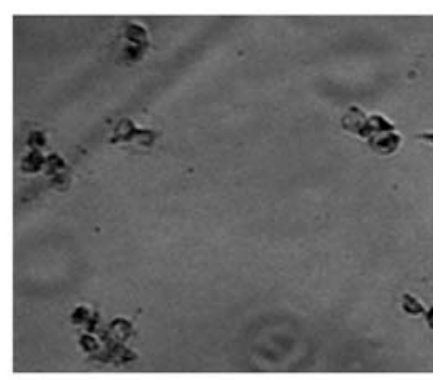

Cisplatin + CuB (36 hrs)

Figure 4. CuB synergistically potentiates the anti-proliferative effects of cisplatin. (A and B) Proliferation of SRB1 and SRB12 cells cultured with either CuB $\left(10^{-7} \mathrm{M}\right.$ or $\left.2.5 \times 10^{-7} \mathrm{M}\right)$, cisplatin [(cis), 5,10 and $\left.20 \mu \mathrm{M}\right]$, or a combination of both was determined by MTT assay. ${ }^{* *} \mathrm{p}<0.01(\mathrm{C})$ SRB12 cells were cultured either without or with $\mathrm{CuB}\left(2.5 \times 10^{-7} \mathrm{M}\right)$ and/or cisplatin $(10 \mu \mathrm{M})$ for $36 \mathrm{~h}$ and examined by light microscopy (x40).

Furthermore, the morphology of SRB12 cells was examined under optical microscopy after $36 \mathrm{~h}$ exposure to $\mathrm{CuB}$ $\left(2.5 \times 10^{-7} \mathrm{M}\right)$, cisplatin $(10 \mu \mathrm{M})$, or a combination of both (Fig. 4C). No prominent alterations in cell morphology were observed in cells exposed to either $\mathrm{CuB}$ or cisplatin alone compared with diluent control cells. However, after treatment with both $\mathrm{CuB}$ and cisplatin at these concentrations, the cells lost their pseudopodia and became refractile (apoptotic appearing) (Fig. 4C).

\section{Discussion}

$\mathrm{CuB}$ is extracted from Trichosanthes kirilowii Maximowicz (Cucurbitaceae family), the fruits and roots of which have long been utilized in traditional Asian medicine for their antiinflammatory, anti-diabetic and abortifacient effects (15). In modern medicine, its anti-proliferative potential is of particular interest, which have been studied in leukemia and a variety of solid tumors $(10,12,14-16,18)$. In this study, we examined for the first time the anti-proliferative effect of $\mathrm{CuB}$ against CSCC cell lines. Sensitivity to the anti-proliferative activity of $\mathrm{CuB}$ differed largely among the cell lines $\left(\mathrm{ED}_{50}\right.$ at $72 \mathrm{~h}$ : averaged between $4 \times 10^{-7} \mathrm{M}$ and $10^{-5} \mathrm{M}$ ). The clonogenic assay also confirmed the growth inhibitory effect of $\mathrm{CuB}$ using a soft agar assay.

To elucidate the mechanism by which $\mathrm{CuB}$ inhibited cell growth of CSCC, Annexin V assay and cell cycle analyses were conducted. A moderate increase in apoptosis (up to $24 \%$ ) occurred after exposure to $10^{-6} \mathrm{M} \mathrm{CuB}$ for $48 \mathrm{~h}$. Flow cytometry analysis revealed that $\mathrm{CuB}$ caused significant accumulation of CSCC cells at the G2-M phase with a decrease of cells in S-phase. CuB also caused a G2-M cell cycle arrest in laryngeal squamous cell carcinoma cells, glioblastoma multiforme cells, and pancreatic cancer cells $(12,14,15)$. In contrast, $\mathrm{CuB}$ induced a $\mathrm{S}$ phase arrest of leukemia cells and hepatocellular carcinoma cells $(10,16)$. The explanation for these differences is unclear. Western blot analysis showed that cell cycle regulators, $\mathrm{CDC} 2$ and cyclin $\mathrm{B} 1$, were downregulated in a dose- and time-dependent manner in CSCC cells. These proteins are responsible for the G2-M phase transition. Our findings paralleled those of Thoennisses et al (14) showing that $\mathrm{CuB}$ decreased expression of Cyclin $\mathrm{B} 1$ and arrested the cell cycle in the G2-M phase in pancreatic cancer cells.

Previous studies from our group demonstrated $\mathrm{CuB}$ can disrupt F-actins and microtubules in glioma, leukemia, as well as breast cancer cells $(15,16,18)$. Given that the F-actin and 
the microtubule cytoskeleton is a key component involved in cell migration, we tested the ability of $\mathrm{CuB}$ to affect cell migration and found that $\mathrm{CuB}$ inhibited migration of CSCC cells. In addition, a short exposure $(<60 \mathrm{~min})$ to $\mathrm{CuB}$ made the CSCC cells become round and refractile (Fig. 2A). These CSCC cells could recover to their normal morphology, if after $60 \mathrm{~min}$ of $\mathrm{CuB}$ exposure the cells were washed free of the drug and cultured for an additional $24 \mathrm{~h}$. This is similar to morphologic changes noted in glioma, pancreatic and breast cancer cells $(14,15,18)$.

Our pulse-exposure experiments showed that a 24-h exposure to $\mathrm{CuB}\left(10^{-7} \mathrm{M}\right)$ largely inhibited growth of CSCC cells, while a shorter ( 2 or $9 \mathrm{~h}$ ) exposure did not produce much growth inhibition. Additionally, CSCC cells which were pulse-exposed to $\mathrm{CuB}$ developed prominent multinucleation, a sign of failed mitosis. This multinucleation phenomenon has also been observed in glioma and pancreatic cancer cells after pulse-exposure to $\mathrm{CuB}(14,15)$.

Metastatic CSCC is poorly treated by conventional therapies including cisplatin. Our in vitro studies showed that $\mathrm{CuB}\left(2.5 \times 10^{-7} \mathrm{M}\right)$ could potentiate the cell killing mediated by cisplatin (10-20 $\mu \mathrm{M})$. Further in vivo studies are warranted to extend these findings.

In summary, the present study showed for the first time that $\mathrm{CuB}$ has profound anti-CSCC activity in vitro. The agent inhibits cellular growth and migration as well as arrests the cell cycle at the G2-M phase in concert with decreasing the expression of CDC2 and cyclin B1. This compound also produces multinucleation and potentiates the antiproliferative activity of cisplatin. Our studies provide a rationale for the development of $\mathrm{CuB}$ as a therapeutic agent against human CSCC.

\section{Acknowledgements}

This study was supported in part by National Institute of Health ROI CA026038-32, and A ${ }^{x}$ STAR award of Singapore (H.P.K). H.P.K. is a member of the Molecular Biology Institute and Jonsson Comprehensive Cancer Center at UCLA, and holds the endowed Mark Goodson Chair of Oncology Research at Cedars-Sinai Medical Center/UCLA School of Medicine.

\section{References}

1. McGuire JF, Ge NN and Dyson S: Nonmelanoma skin cancer of the head and neck I: histopathology and clinical behavior. Am J Otolaryngol-Head Neck Med Surg 30: 121-133, 2009.

2. Martinez JC and Cook JL: High-risk cutaneous squamous cell carcinoma without palpable lymphadenopathy: Is there a therapeutic role for elective neck dissection? Dermatol Surg 33: 410-420, 2007.

3. Weinberg AS, Ogle CA and Shim EK: Metastatic cutaneous squamous cell carcinoma: An update. Dermatol Surg 33: 885-899, 2007.

4. Trakatelli M, Ulrich C, Del Marmol V, Euvard S, Stockfleth E and Abeni D: Epidemiology of nonmelanoma skin cancer (NMSC) in Europe: Accurate and comparable data are needed for effective public health monitoring and interventions. Br J Dermatol 156: 1-7, 2007.

5. Alam M and Ratner D: Cutaneous squamous-cell carcinoma. N Engl J Med 344: 975-983, 2001.

6. Langer CJ: Targeted therapy in head and neck cancer: State of the art 2007 and review of clinical applications. Cancer 112: 2635-2645, 2008.

7. Argiris A, Karamouzis MV, Raben D and Ferris RL: Head and neck cancer. Lancet 371: 1695-1709, 2008.

8. Yang L, Wu S, Zhang Q, Liu F and Wu P: 23,24-Dihydrocucurbitacin $\mathrm{B}$ induces $\mathrm{G} 2 / \mathrm{M}$ cell-cycle arrest and mitochondriadependent apoptosis in human breast cancer cells (Bcap37). Cancer Lett 256: 267-278, 2007.

9. Escandell JM, Kaler P, Recio MC, et al: Activated kRas protects colon cancer cells from cucurbitacin-induced apoptosis: The role of p53 and p21. Biochem Pharmacol 76: 198-207, 2008.

10. Zhang M, Zhang H, Sun C, et al: Targeted constitutive activation of signal transducer and activator of transcription 3 in human hepatocellular carcinoma cells by cucurbitacin B. Cancer Chemother Pharmacol 63: 635-642, 2009.

11. Chan KT, Li K, Liu SL, Chu KH, Toh M and Xie WD: Cucurbitacin B inhibits STAT3 and the Raf/Mek/Erk pathway in leukemia cell line K562. Cancer Lett 289: 46-52, 2009.

12. Liu T, Zhang M, Zhang H, Sun C and Deng Y: Inhibitory effects of cucurbitacin B on laryngeal squamous cell carcinoma. Eur Arch Oto-Rhino-Laryngol 265: 1225-1232, 2008.

13. Liu T, Zhang M, Zhang H, et al: Combined antitumor activity of cucurbitacin B and docetaxel in laryngeal cancer. Eur J Pharmacol 587: 78-84, 2008.

14. Thoennissen NH, Iwanski GB, Doan NB, et al: Cucurbitacin B induces apoptosis by inhibition of the JAK/STAT pathway and potentiates antiproliferative effects of gemcitabine on pancreatic cancer cells. Cancer Res 69: 5876-5884, 2009.

15. Yin D, Wakimoto N, Xing H, et al: Cucurbitacin B markedly inhibits growth and rapidly affects the cytoskeleton in glioblastoma multiforme. Int J Cancer 123: 1364-1375, 2008.

16. Haritunians T, Gueller S, Zhang L, et al: Cucurbitacin B induces differentiation, cell cycle arrest, and actin cytoskeletal alterations in myeloid leukemia cells. Leuk Res 32: 1366-1373, 2008.

17. Sun J, Blaskovich MA, Jove R, Livingston SK, Coppola D and Sebti SM: Cucurbitacin Q: a selective STAT3 activation inhibitor with potent antitumor activity. Oncogene 24: 3236-3245, 2005.

18. Wakimoto N, Yin D, O'Kelly J, et al: Cucurbitacin B has a potent antiproliferative effect on breast cancer cells in vitro and in vivo. Cancer Sci 99: 1793-1797, 2008. 